\title{
Resistências dos Movimentos Sociais e ONGs frente ao Avanço do Agronegócio no Oeste da Amazônia Paraense
}

\author{
Resistance of Social Movements and NGOs in the face of Advancement of \\ Agribusiness in in the Amazon Western Region of the Pará State
}

\section{Resistencias de los Movimientos Sociales y Ongs frente al Avance del Agronegocio en el Oeste de la Amazonia Paraense}

Rayla de Lima Tavares ${ }^{1}$

Francilene Sales da Conceição ${ }^{2}$

Antonio Celso Serique de Castro Filho ${ }^{3}$

RESUMO: Este trabalho tem como objetivo analisar o papel dos movimentos sociais e organizações não governamentais (ONGs) frente ao avanço do agronegócio que se cristaliza no oeste do estado do Pará, região do Baixo Amazonas, no contexto da Geografia Agrária. Essa temática vem sendo muito debatida e enfrentada pelos movimentos sociais e ONGs no oeste paraense. A metodologia utilizada se deu por meio da revisão teórica conceitual e do trabalho de campo, com uso da técnica de entrevistas semiestruturadas com membros representantes de movimentos sociais e ONGs, bem como também registros de imagens do ambiente investigado. Nota-se que a partir da territorialização da agricultura capitalista e hegemônica houve mudanças das paisagens na região que metamorfoseou as relações socioespaciais e socioterritoriais. Nesse sentido, a implementação de sistemas logísticos (portos, hidrovias e rodovias) no oeste da Amazônia Paraense corrobora o acirramento e a materialização da grilagem de terras, dos conflitos agrários e territoriais, da manutenção da propriedade privada e da concentração fundiária.

PALAVRAS-CHAVE: Geografia agrária. Movimentos sociais. Agronegócio. Amazônia paraense.

\begin{abstract}
The aim of this work is to analyze the role of Social Movements and Non - Governmental Organizations (NGOs) in the face of the agribusiness advance that remains fixed in the western state of Pará, in the Lower Amazon region, in the context of agrarian geography. This theme has been much debated and faced by Social Movements and NGOs in western of Pará. The methodology used occurred by mean of the theoretical conceptual revision and the fieldwork, using the technique of semi-structured interviews with members representing Social Movements and NGOs, as well as

\footnotetext{
${ }^{1}$ Curso de Licenciatura em Geografia pela Universidade Federal do Oeste do Pará (UFOPA). Av. Marechal Rondon S/N, campus RONDON, Santarém/PA - 68040-070. rayladelimatavares@gmail.com.

${ }^{2}$ Curso de Licenciatura em Geografia pela Universidade Federal do Oeste do Pará (UFOPA). Av. Marechal Rondon S/N, campus RONDON, Santarém/PA - 68040-070. lenesalesgeo@hotmail.com.

${ }^{3}$ Curso de Licenciatura em Geografia pela Universidade Federal do Oeste do Pará (UFOPA). Av. Marechal Rondon S/N, campus RONDON, Santarém/PA - 68040-070. celsoserique@hotmail.com.
} 
image records were made of the investigated area. It is noted that from the territorialization of capitalist and hegemonic agriculture, there were changes of the landscapes in the region and metamorphosed the socio-spatial and socio-territorial relations. In this perspective the implementation of logistic systems (ports, waterways and highways) in the western part of the Amazon region of the Pará state, corroborates the aggravation and materialization of land grabbing, agrarian and territorial conflicts, maintenance of private property and land concentration.

KEYWORDS: Agrarian geography. Social movements. Agribusiness. Amazonia paraense.

RESUMEN: Este trabajo tiene como objetivo analizar el papel de los Movimientos Sociales y Organizaciones no Gubernamentales (ONG) frente al avance del agronegocio que se cristaliza en el oeste del estado de Pará, región del Bajo Amazonas, en el contexto de la geografía agraria. Esta temática viene siendo muy debatida y enfrentada por los Movimientos Sociales y ONGs en el oeste paraense. La metodología utilizada se dio por medio de la revisión teórica conceptual y el trabajo de campo, con uso de la técnica de las entrevistas semiestructuradas con miembros representantes de Movimientos Sociales y ONGs, así como también hubo registros de imágenes del ambiente investigado. Se nota que a partir de la territorialización de la agricultura capitalista y hegemónica, hubo cambios de los paisajes en la región y metamorfoseó las relaciones socioespaciales y socioterritoriales. En este sentido, la implementación de sistemas logísticos (puertos, hidrobias y carreteras) en el oeste de la Amazonia Paraense, corrobora con el agravamiento y la materialización del grillaje de tierras, de los conflictos agrarios y territoriales, del mantenimiento de la propiedad privada y de la concentración agraria.

PALABRAS-CLAVE: Geografía agraria. Movimientos sociales. Agroindustria. Amazonas paraense.

\section{INTRODUÇÃO}

O desenvolvimento do capitalismo (agronegócio) no espaço agrário brasileiro promove a negação de múltiplas territorialidades dos povos tradicionais e originários, bem como vem provocando diversos enfrentamentos e resistências pelos sujeitos do campo, das águas e das florestas.

Na Amazônia, as dinâmicas agrárias e territoriais se tornam complexas, na medida em que o capital global se territorializa na região, modificando os lugares em suas múltiplas dimensões e escalas espaciais. As populações camponesas, indígenas, quilombolas, extrativistas, ribeirinhas e caboclas são as principais classes afetadas no interior desses territórios em disputas, pois seus modos de vida se tornam alvo da subjugação/exclusão, em virtude do capital ter avançado e se apropriado de territórios, transformando as terras, as águas e as florestas em mercadoria para atender uma demanda exógena.

Este artigo objetiva analisar o papel dos movimentos sociais e organizações não governamentais (ONGs) frente ao avanço do agronegócio que se cristaliza na região oeste do estado do Pará, no contexto da Geografia Agrária.

Essa temática vem sendo muito debatida e enfrentada pelos Movimentos Sociais e ONGs no oeste paraense, pois essa região possui um alto grau de resistência frente à 
fronteira móvel do capital mundializado, sendo que são esses grupos que lutam e resistem conjuntamente com os povos do campo, das águas e das florestas. As principais pautas de lutas e reivindicações dessas populações amazônidas são: valorização da vida, ter o direito de permanecer na terra e no território e a busca pelo reconhecimento dos direitos humanos e territoriais. Entretanto, o discurso e a proposta hegemônica executada instaura a negação da existência desses trabalhadores do campo, das águas e das florestas, além de promover, a cada dia, a criminalização dos movimentos sociais e demais organizações. O recorte espacial da área de estudo é o oeste do estado do Pará (Figura 1), situado na região do Baixo Amazonas, Amazônia brasileira.

Figura 1 - Mapa de localização da área de estudo

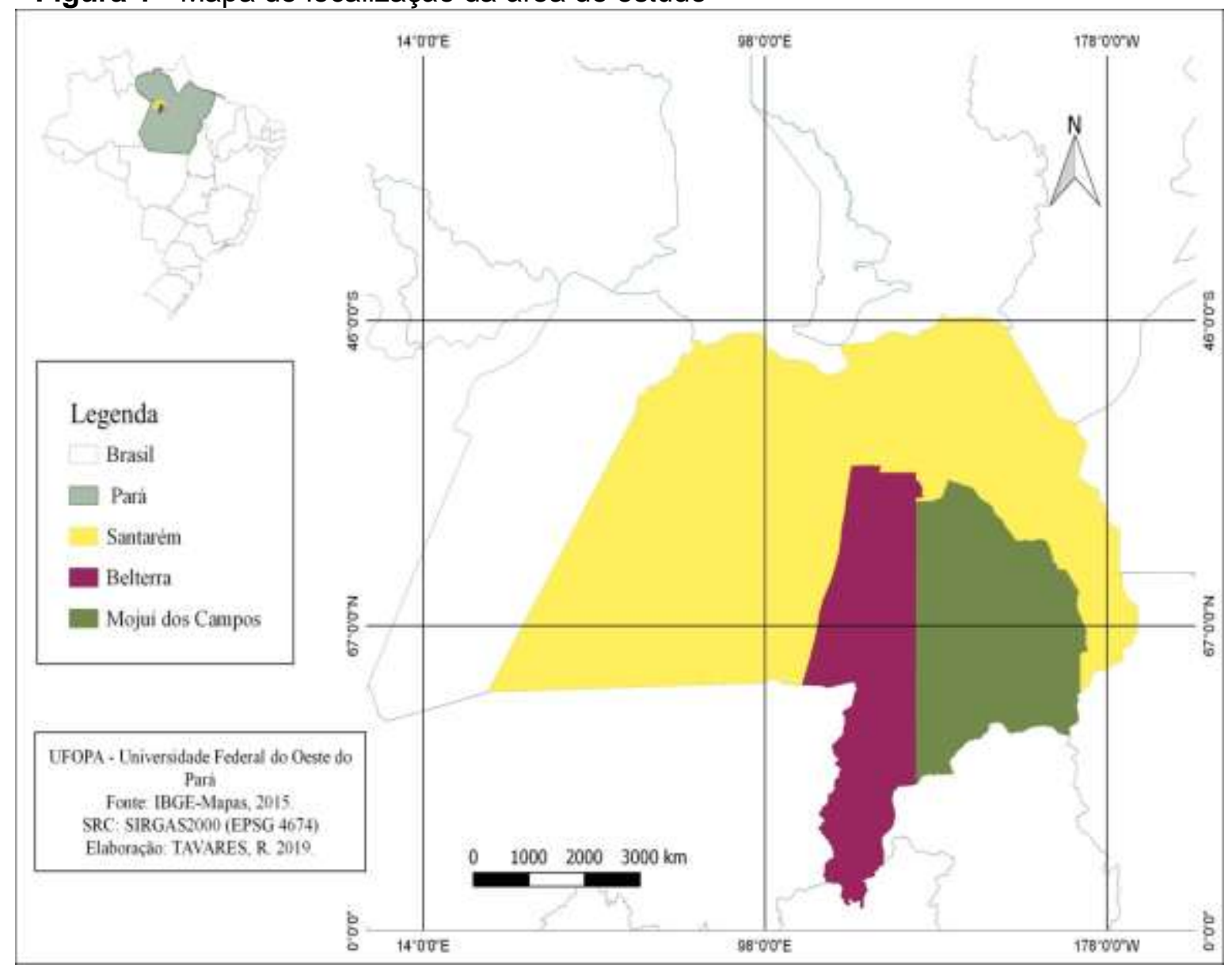

Fonte: elaborado por Tavares a partir de IBGE (2015).

A metodologia utilizada se deu por meio da revisão teórica conceitual (CONCEIÇÃO, 2017; FABRINI, 2008; FERNANDES, 2008, 2013, 2015; OLIVEIRA, 2007; PEDON, 2013) e o trabalho de campo, com uso da técnica da entrevista. Foram aplicadas entrevistas semiestruturadas e conversas informais, utilizando-se do caderno de campo para registro de informações coletadas dos movimentos sociais e ONGs da região oeste do Pará, bem como foi realizado ainda, registros fotográficos e produções cartográficas. 
Nos estudos e levantamentos realizados nos anos 2017 e 2018 percebeu-se que houve mudanças territoriais e da paisagem nessa região. A territorialização do agronegócio, iniciada na década de 1990 e intensificada na década de 2000, materializou a expansão e a reprodução da agricultura capitalista e instaurou a "modernização da agricultura" excludente e contraditória nas comunidades rurais.

O Planalto Santareno (Santarém, Belterra e Mojuí dos Campos) se configura como um grande celeiro agrícola, uma vez que a monocultura da soja vem expropriando os trabalhadores rurais e implementando a grilagem de terras, a apropriação dos recursos naturais, a manutenção da propriedade privada e a concentração fundiária e a instalação de multinacionais e redes de infraestruturas (portos, rodovias e hidrovias), resultando na articulação, mobilização e organização das frentes de resistências, representados pelos movimentos sociais e ONGs.

\section{MOVIMENTOS SOCIAIS E TERRITORIALIZAÇÃO CAMPONESA: UM DEBATE TEÓRICO-METODOLÓGICO EM GEOGRAFIA AGRÁRIA}

As ações e a organização do campesinato em movimentos sociais é uma estratégia de luta e resistência contra a hegemonia capitalista que se cristaliza nos múltiplos territórios (HAESBAERT, 2004) do espaço agrário. Essa classe social se manifesta como uma categoria política que está à frente das lutas sociais, reivindicando os direitos humanos, territoriais e ambientais dos povos do campo-águas-floresta.

O campesinato se territorializa e, com ele, surgem as lutas no campo, como uma forma de alcançar e preservar as conquistas territoriais históricas. Pelo fato do território ser relacional e estar em disputa, as lutas dos camponeses/camponesas são contra o modo de produção capitalista, pois esse modelo exclui, contraria, subordina e criminaliza os trabalhadores rurais. Por isso, a estratégia de recriação social dos pequenos agricultores é a prática da produção autônoma, soberania alimentar, subsistência e renda familiar, e relações de proximidades e familiares (solidariedade orgânica).

A reminiscência da territorialidade camponesa comprova que os sujeitos do campo vivem sob a lógica da natureza e não do capital. Mas a partir da incorporação de políticas públicas voltadas para o setor produtivo, a exemplo dos investimentos direcionados ao agronegócio, a inciativa privada, sob o comando da burguesia agrária com o expresso apoio estatal, cria um panorama socioespacial e socioterritorial do mundo agrário metamorfoseado, cujo escopo final do processo é ceder lugar à reprodução ampliada do capital configurada na ordem da escala-mundo. 
Nesse contexto, a questão agrária no Brasil, conforme Oliveira (2007) se dá a partir da expansão e do desenvolvimento do capitalismo no campo, porque o espaço agrário brasileiro sempre foi alvo da luta pela terra. Esse processo hegemônico promove um movimento desigual e combinado e instaura uma monopolização do território e territorialização do capital, no qual produzem espaços segregados e conflitantes. Portanto, é importante que a sociedade civil organizada busque formas de representação e reprodução social frente aos planos, programas, projetos e ações hegemônicas.

O Estado é o principal agente que cria condições para a expansão do latifúndio nos territórios do campesinato e legitima os conflitos fundiários e territoriais. Portanto, na agricultura a renda da terra é subordinada ao capital, uma vez que o processo de expansão do capital no campo se dá por meio da compra e venda da terra ou pela subordinação da produção camponesa (OLIVEIRA, 2007). Há uma disputa territorial entre a agricultura camponesa e a agricultura capitalista.

[...] pode-se compreender as conflitualidades entre modelos de desenvolvimento que disputam territórios, condição essencial para a sua expansão. Estamos nos referindo especialmente aos modelos de desenvolvimento do agronegócio, resumidamente a partir da produção de monoculturas em grande escala, com trabalho assalariado, intensamente mecanizado e com utilização de agrotóxicos e sementes transgênicas. $E$ ao modelo de desenvolvimento do campesinato ou agricultura familiar, resumidamente a partir da produção de policulturas, em pequena escala, com predominância do trabalho familiar, com baixa mecanização, em sua maior parte, com base na biodiversidade sem a utilização de agrotóxicos (FERNANDES, 2008, p. 281).

Os camponeses têm se distanciado das margens das rodovias para lugares mais afastados, pois com a expansão do cultivo da soja não estão conseguindo produzir devido aos elevados usos de agrotóxicos aplicados nas monoculturas pelos grandes produtores. Dessa forma, “[...] o capital tem o poder de se territorializar mais rápido que o campesinato por causa das desigualdades geradas pelo modo de produção capitalista, que expropria o campesinato de seus territórios" (FERNANDES, 2008, p. 296).

Essa é a realidade enfrentada pelas comunidades rurais camponesas. Seus territórios vêm sofrendo pressões territoriais por parte dos grandes produtores, em que esse "modelo de desenvolvimento" (agronegócio) ameaça os modos de vidas tradicionais do campesinato por meio de sua lógica hegemônica forçada, tornando o território um campo de forças. "No desenvolvimento da agricultura há uma permanente disputa territorial por causa dos interesses do campesinato, do agronegócio e dos governos" (FERNANDES, 2013, p. 48). Essas disputas ocorrem pela heterogeneidade desses grupos e suas diferentes perspectivas em relação ao território, assim estes conflitos estão sempre presentes na vida dos camponeses da região, que lutam pelos seus interesses e pelo seu território. 
Segundo Teubal (2008), com o avanço do agronegócio os conflitos pela terra aumentam devido à ambição dos invasores. Com isso, são duas classes que diferem e são produtoras de territórios. É importante ressaltar que o lugar social dos camponeses se faz na luta e resistência em diferentes espaços e momentos históricos.

A Geografia, como uma ciência que vê o espaço como um produto da ação social, vem estudando os movimentos sociais (campo ou na cidade), a partir de suas práticas sócio-espaciais emancipatórias, cristalizadas nas categorias de Autogestão, "Autoplanejamento" e Autonomia (SOUZA, 2004, 2016). Dessa forma, é sabido que os movimentos sociais no contexto da Geografia Crítica, a partir de 1970, ganhou maior destaque, porque a luta política possibilitou aos movimentos sociais importantes conquistas. Lutaram contra o avanço do modo de produção capitalista, pela permanência do pensamento libertário e pela legitimação de diversos direitos, envolvendo não apenas a classe social do campesinato, mas lutas e resistências que ocorreram em outras esferas e segmentos sociais.

Os movimentos sociais podem ser caracterizados como manifestações organizadas da sociedade civil com o objetivo de contestar a ordem estabelecida e a maneira como a sociedade está organizada. Eles estão presentes na luta por grandes transformações da sociedade, tais como luta por mudanças no sistema econômico e modo de produção, bem como reivindicações localizadas e ligadas à cidadania e garantia de direitos. Assim, as ações coletivas contemporâneas realizadas nos movimentos podem ser manifestações dos operários pela melhoria das condições salariais e de trabalho luta dos camponeses pela terra, bem como os movimentos de natureza cultural, étnica, etária etc. (FABRINI, 2008, p. 240).

É nesse contexto, marcado pela geograficidade dos movimentos sociais organizados, que os debates acerca da Geografia Agrária começam a ganhar mais ênfase. A luta pela terra e as disputas territoriais entre as classes sociais se multiplicam, na medida em que o capitalismo avança no espaço agrário brasileiro, explora a força de trabalho e mercantiliza as relações sociais e suas dimensões espaciais. As (re)existências do campesinato e o sentido da força coletiva dos grupos de resistências ancoradas nos movimentos sociais são importantes para o alcance de suas conquistas e pela busca por uma sociedade mais humanitária, que valorize o direito dos trabalhadores do campo de viver, existir e persistir na terra e no território.

As metas traçadas pelo movimento para a conquista do território devem integrar ações coletivas, manifestando-se ativos por meio de protestos e denúncias para a solução dos problemas e indicando prerrogativas para a mudança da mentalidade e de modelos de projetos autoritários que interferem no direito do acesso e à permanência na terra e no território. "As mobilizações coletivas podem ser compreendidas como uma forma de 
agrupamentos de pessoas que busca organizar suas ações com o objetivo de obter respostas às suas demandas." (PEDON, 2013, p. 197). Assim, as pautas incorporadas nas agendas dos movimentos sociais buscam por respostas imediatas pelas dificuldades enfrentadas e pelo reconhecimento identitário e territorial, haja vista que a mobilidade socioespacial de representação está fundamentada no lema: lutar, resistir e produzir.

Os movimentos sociais têm um papel preponderante nas políticas de organização do espaço agrário e territorial. Conforme Fernandes (2015) a luta não é somente pela terra, mas pelo território, qualificando a importância que possuem os movimentos sociais e organizações na formulação de políticas públicas. Para tanto, afirma que as políticas dos territórios camponeses devem ser elaboradas pelos camponeses, sindicatos e suas confederações, não podendo ser organizadas e elaboradas seguindo a lógica do agronegócio. As políticas públicas devem ser formuladas de acordo com as características, demandas e reais necessidades em que vivem e moram os povos do campo, das águas e das florestas, nos quais se sintam contemplados na agenda política peculiar.

Segundo Fernandes (2008, p. 280): "As propriedades camponesas e as capitalistas são territórios distintos, são totalidades diferenciadas, nas quais se produzem relações sociais diferentes, que promovem modelos divergentes de desenvolvimento". A priori, a partir do ano de 1997, o agronegócio se territorializou na região oeste do Pará com o apoio do Estado e transformou o campo-cidade, a exemplo dos municípios de Santarém, Mojuí dos Campos e Belterra, no oeste da Amazônia paraense, na ordem técnica, psicológica, estrutural e conjuntural.

A agricultura capitalista se apropriou do território implantando um modo de produção hegemônico sem se preocupar com o modo de vida das populações tradicionais da região do Baixo Amazonas, causando conflitos entre os camponeses e os grandes latifundiários. Os camponeses têm uma relação de reproduzir seu modo de vida, como a agricultura de subsistência, a pesca e o extrativismo, não apenas por meio da acumulação de capital, cujas territorialidades e espacialidades se fundamentam na tríade: terra-água-floresta (CONCEIÇÃO; RIBEIRO; COSTA SILVA, 2019). Por outro lado, para o agronegócio, a terra é somente espaço de produção de capital e não de reprodução da vida.

A partir do avanço do agronegócio no oeste da Amazônia Paraense, os movimentos sociais de (re)existências se articularam e vem clamando pelo direito a uma vida digna e por justiça social e ter o direito de permanecer e se recriar na terra e no território. Por isso, essa região apresenta um grau de resistência significativo frente aos projetos arquitetados pela racionalidade capitalista:

A história de Santarém e Belterra faz com que os conflitos gerados pela introdução dos vastos campos de soja não se limitem àqueles referentes à titulação e uso da terra. Mais que isso, e apesar das muitas derrotas ante o 
poder econômico, a região apresenta um grau de organização e resistência de seus trabalhadores rurais raramente alcançado em qualquer outra região do Brasil (SCHLESINGER; NORONHA, 2006, p. 73).

O oeste da Amazônia paraense se destaca por meio da espacialização dos conflitos, em virtude do agronegócio sojeiro ter avançado no campo. Fala-se em territórios das resistências dos trabalhadores do campo, que enxergam na terra e no território a possibilidade de exercer o trabalho e ter o direito ao lugar de morada e de garantir a reprodução social da vida, ao contrário da lógica do agronegócio, que vê a terra como mercadoria. Sendo assim, as populações camponesas, indígenas, quilombolas, extrativistas, ribeirinhas e caboclas vêm sendo alvo da subjugação/exclusão de seus modos de vidas, em virtude do capital ter avançado, apropriando-se de territórios e transformado as terras, as águas e as florestas em mercadoria para atender uma demanda exógena.

A sedimentação desse processo espoliador é a territorialização de monopólios, a monopolização (OLIVEIRA, 2007) e o estabelecimento de um corporativismo no território, no qual esse processo é materializado não apenas na forma do cultivo agrícola, mas na construção de grandes tradings (empresas multinacionais ou transnacionais), a exemplo da empresa Cargill em Santarém/PA, que comandam os mercados mundiais e criam estratégias corporativas no território. É contra essas ações hegemônicas no oeste do estado do Pará que os movimentos sociais vêm lutando, resistindo e persistindo, criando suas próprias normas e regras para garantir a territorialização e a espacialização de suas lutas, que se reproduzem socialmente nos múltiplos territórios amazônicos.

\section{MOVIMENTOS SOCIAIS NO ESTADO DO PARÁ: ESPACIALIZAÇÃO DAS LUTAS SOCIAIS E ESTRATÉGIAS DE RECRIAÇÃO SOCIAL}

Os movimentos sociais e ONGs na região oeste do estado do Pará (Figura 2) lutam contra a criminalização e a exploração e a subordinação do Estado à burguesia do agronegócio e das corporações do agronegócio. Nesse contexto, essas organizações têm o papel fundamental em conter o avanço da monocultura da soja, pois esse modo de produção hegemônico implantado na região causa diversos impactos sociais, ambientais e culturais.

Os povos dessa região possuem um grau de resistência significativo frente à fronteira móvel do capital mundializado. É nesse sentido que os movimentos sociais organizados e as ONGs que defendem os direitos humanos, ambientais e culturais dos povos e comunidades tradicionais amazônicas têm se mobilizado e formulado estratégias de lutas para o enfrentamento do capitalismo. Entretanto, o discurso e a proposta hegemônica da 
reprodução ampliada do capital nega as existências desses trabalhadores rurais e acirram a criminalização dos movimentos sociais e demais organizações.

Figura 2 - Mapa de localização dos Movimentos Sociais e ONG, região oeste do Pará

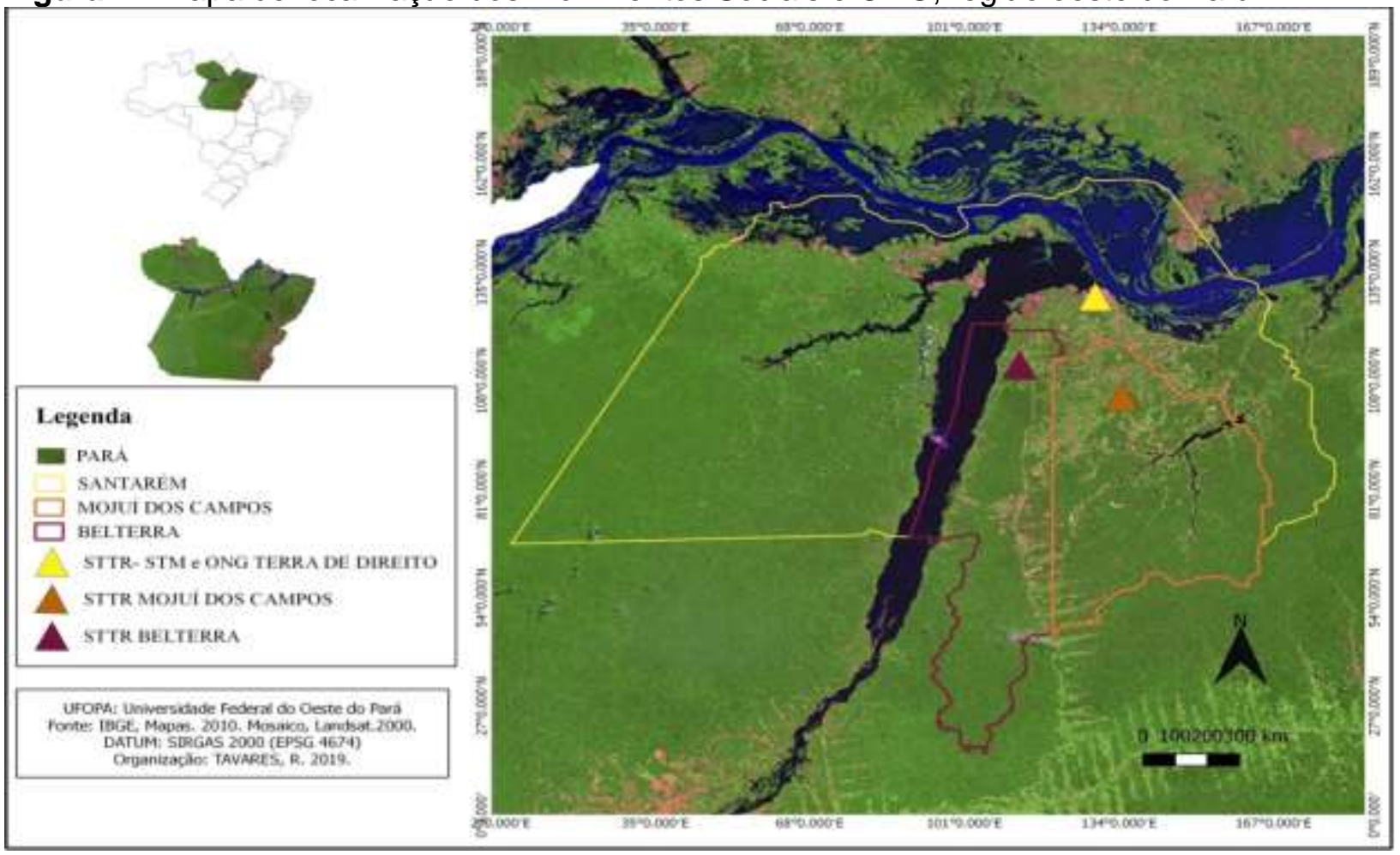

Fonte: elaborado por Tavares a partir de IBGE (2010).

O principal ponto pauta de articulações desses movimentos de resistências organizados é: evitar o êxodo rural, pois os grandes latifundiários compram as terras de camponeses por um valor baixíssimo. Assim, esses camponeses/camponesas migram para lugares distantes no próprio campo, e além de sofrer pelo processo de expropriação de seus territórios, os que permanecem tentando produzir enfrentam os problemas de contaminação dos corpos d'água e de elevado uso de agrotóxicos usados pela agricultura de grande escala, pondo em risco a saúde da população. Nas cidades, muitas vezes acabam indo residir nas áreas "periféricas", ocasionando ocupação desordenada e, por essas áreas não receberem os serviços de infraestrutura básica, ocorrem inúmeros processos de degradação ambiental, principalmente pela falta de um planejamento e de um ordenamento territorial.

Os movimentos sociais "[...] tem tornado cada vez mais evidente a necessidade de se elaborar uma estratégia de desenvolvimento para o campo que priorize as oportunidades de desenvolvimento social e não se restrinja a uma perspectiva estritamente econômica e setorial" (MARQUES, 2002, p. 96). Por isso, as políticas públicas devem ser construídas pelos próprios sujeitos do campo e demais organizações que estão em movimento no campo, e a principal pauta de suas agendas deve ser o desenvolvimento humano e 
territorial dos povos do campo, das águas e das florestas e não somente o melhoramento do setor produtivo que verticaliza a produção e de alcance da escala-mundo.

A década de 1990 foi o marco da instalação do agronegócio na região oeste do Pará, e houve a colaboração dos governos municipais da época (Santarém, Mojuí dos Campos e Belterra). Assim, a agricultura capitalista se apropriou do território implantando um modo de produção hegemônico sem preocupar-se com o modo de vida das populações tradicionais, causando conflitos entre os camponeses e os grandes latifundiários e dos povos amazônicos com as corporações do agronegócio. Para o campesinato a terra e o território é morada, subsistência, trabalho e reprodução da vida, enquanto que, para o agronegócio, a terra é somente espaço de produção e de acumulação de capital.

A região oeste do estado do Pará têm atraído grandes produtores de soja a partir de planos estratégicos do Estado. Esses planos impostos pelo Estado na região não consideram o modo de vida das comunidades tradicionais, desterritorializando-as e, em alguns casos, ocasionando problemas de saúde nessa população, pelo uso excessivo de agrotóxicos e a degradação ambiental como é o caso da Praia da "Vera Paz".

A empresa multinacional Cargill Agrícola S.A. (Figura 3) se territorializou na frente da cidade de Santarém - Pará, sem que houvesse estudos de impacto ambiental (EIA) e a construção do Relatório de Impacto Ambientai (RIMA) pelos órgãos competentes para a instalação do porto graneleiro. Esse fato resultou na extinção da praia, alterando a paisagem e a multidimensionalidade do vivido, ou seja, a praia, que era um espaço público, frequentada pelas pessoas da região oeste do Pará que buscavam lazer e diversão e que era carregada de significados simbólicos e do imaginário, transformou-se em propriedade privada, onde o poder exercido pela empresa subordinou a lógica local a um circuito global.

Segundo Conceição (2017), os movimentos sociais e os grupos ambientalistas foram contrários à instalação desse empreendimento e, mesmo com reivindicações, clamores e resistências, não conseguiram barrar a instalação dessa corporação do agronegócio, haja vista que existia uma união já estabelecida entre o governo municipal e a empresa norteamericana Cargill. Portanto, a região é palco do cultivo de soja, pois a produção nessa área é mais viável economicamente para os grandes latifundiários.

[...] enquanto os produtores dos municípios de Sinop e Sorriso, em Mato Grosso, pagam até $R \$ 150,00$ por $1.000 \mathrm{~kg}$ de frete até ao Porto de Santarém, os produtores da região pagam, em média, $R \$ 15,00$ por 1.000 $\mathrm{kg}$ constituindo uma vantagem competitiva locacional de custo do produto para os produtores de Santarém e Belterra (OLIVEIRA; SANTANA; HOMMA, 2013, p. 28).

Com o avanço do agronegócio, precisou-se de mais terras para o cultivo agrícola e, com isso, aumenta a concentração fundiária, a valorização e o condicionamento do espaço 
agrário, além de apropriação indevida dos recursos naturais e as transformações geográficas nos territórios das populações amazônidas e nos seus respectivos modos de vida (CONCEIÇÃO, 2017). A territorialização do capital no espaço agrário mantém concentrada a estrutura fundiária e a propriedade privada nas comunidades do planalto santareno e, na cidade, corrobora com a espacialização de redes de multimodais, cristalizado no corporativismo do território e na produção espacial e territorial que está articulada em uma escala mundializada.

Figura 3 - Modal do porto da Cargill às margens do rio Tapajós, cidade Santarém/PA

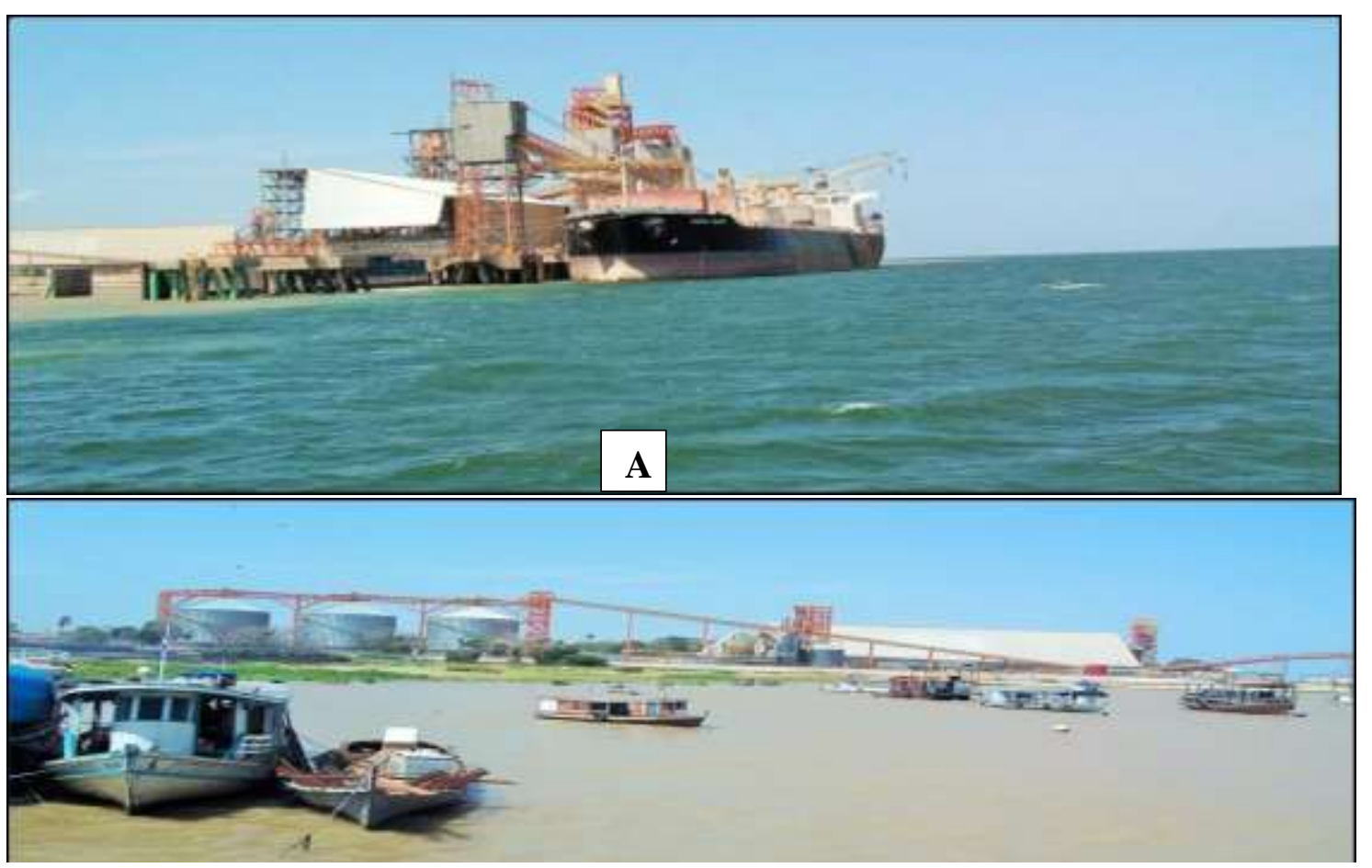

Fonte: Trabalho de campo (2016). Fotografia de Conceição.

A lógica da economia mundializada do agronegócio implementa estranhamentos nos múltiplos territórios da região oeste do Pará e, por isso, os movimentos de resistências se mostram ativos em defesa de seus territórios de vida. Nas áreas onde há produção de soja, nota-se disputas entre os camponeses/indígenas/quilombolas/ribeirinhos e os latifundiários, pois a agricultura capitalista pressiona, invade e incorpora pequenas propriedades das policulturas em grandes propriedades das monoculturas dos agroquímicos.

Os movimentos sociais e ONGs têm se articulado e desenvolvido ações contra o avanço do agronegócio na região do oeste paraense, alertando sobre os impactos e contaminação por agrotóxicos. Os movimentos sociais têm incentivado os pequenos produtores e trabalhadores rurais a não abrirem mão de sua terra e ampliar suas estratégias de produção agroecológica como forma de resistência, garantindo a soberania alimentar e 
uma qualidade de vida mais saudável e autônoma para sua unidade familiar e para os consumidores locais.

\section{MOVIMENTOS SOCIAIS FRENTE AO AGRONEGÓCIO LATIFUNDIÁRIO: AÇÕES E RESISTÊNCIAS NO OESTE DO PARÁ}

O papel dos movimentos sociais e ONGs consiste na articulação em defesa da reprodução social nos territórios dos povos do campo, das águas e da floresta; da existência e da permanência da vida de tais populações; além de se posicionar contrários a esse modelo que oprime, expropria e marginaliza os povos que habitam o espaço amazônico. Nessa perspectiva, na região estudada, temos os movimentos Sindicato dos Trabalhadores Rurais dos municípios de Santarém, Mojuí dos Campos e Belterra e a ONG "Terra de Direitos", que atuam contra os impactos socioambientais, o modo de produção hegemônico e as ações contraditórias do Estado.

Passam a atuar de modo mais nítido a partir da década de 2000, frente à territorialização do agronegócio, que transformou o planalto santareno em um grande celeiro agrícola e instaurou um processo excludente e contraditório marcado pela expropriação dos trabalhadores rurais, pela grilagem de terras, pela manutenção da propriedade privada e concentração fundiária e pela instalação de multinacionais e redes de infraestruturas (portos, rodovias e hidrovias).

Os movimentos sociais se organizam e criam formas de enfrentamentos frente à agricultura capitalista e às corporações do agronegócio da seguinte maneira: o Sindicato dos Trabalhadores Rurais (STTR) do município de Belterra tem se articulado como forma de promover o enfrentamento da expansão da agricultura capitalista. Essas ações de resistências territoriais, objetiva resgatar a identidade do movimento sindical e, para isso, realiza campanhas denominadas "não abra a mão da sua terra", campanha criada pelos Sindicatos dos Trabalhadores Rurais Agricultores e Agricultoras Familiares de Alenquer, Belterra, Mojuí dos Campos, Santarém e a Comissão Pastoral da Terra (CPT). Ressalta-se que a importância de lutar pelo direito de permanecer nas terras que ocuparam há gerações, além de enfatizar a relevância do sindicato como uma ferramenta de luta do agricultor, propicia a informação jurídica e sindical.

Nesse processo de formação e capacitação sindical estão inseridos os jovens, mulheres e lideranças sindicais. Assim, o sindicato se organiza em cooperativas, dentre elas o movimento de mulheres, indígena e das comunidades tradicionais. $\mathrm{E}$, nessa união, surgiu o Fórum dos Movimentos Sociais, que ficou desativado em 2016, mas que foi reativado em 2018. Uma das problemáticas enfrentadas por esse sindicato é a ideologia de um grupo 
contrário aos camponeses, de que a falta do "desenvolvimento" no município de Belterra são os assentamentos e para ir contra essa ideia eles se organizam em atividades de treinamento:

Nós precisamos do assentamento porque é única forma de ter garantia da terra na mão do agricultor familiar, é através desse projeto de assentamento, porque é a forma mais justa da terra ser dividida entre a população, então isso é uma disputa ideológica e que o movimento sindical tem se organizado dessa forma através de formação sindical, nós ir para o enfrentamento. Esse processo de enfrentamento ele perpassa por um longo processo de capacitação das lideranças porque se não, vamos estar com lideranças despreparadas e falando até a linguagem que o defensor do agronegócio quer ouvir (STTR - BELTERRA, em 22/05/2018).

A união, a organização e a perseverança em lutar em prol da defesa de sua terra e seu território são os principais mecanismos utilizados para a reprodução social do movimento sindical belterrense, a fim de resistir contra as forças hegemônicas coercitivas e impostoras do agronegócio. É preciso que as lideranças dos movimentos estejam preparadas e formulem as estratégias de enfrentamentos para suas permanências na terra/território, caso contrário serão incorporadas pela lógica avassaladora do agronegócio e serão excluídas do direito de viver no campo, nas águas e nas florestas.

A luta frente ao agrobusiness deve ser constante, pois esse é um "modelo desenvolvimentista" pensado geoestrategicamente para a região nos próximos anos, em que ameaçam e criminalizam as territorialidades e as espacialidades dos povos da Amazônia paraense. No Sindicato dos Trabalhadores Rurais - STTR de Santarém tanto os povos indígenas quanto os quilombolas fazem parte do sindicato. Dessa forma, os segmentos sociais vêm se tornando parceiros nas lutas sociais no campo, pois é importante que o sindicato também entre na luta em defesa dos territórios e territorialidades.

Outra coisa que estamos discutindo principalmente dentro do território das áreas de unidades de conservação, tanto quem é associado como também quem não é, é a importância do Sistema Nacional da Unidade de Conservação aprender e saber o que realmente significa isso, para que a partir dessa compreensão possam defender seus territórios. Inclusive dentro das áreas quilombolas, os sindicatos de Santarém, nós fomos os primeiros a fazer o cadastro ambiental rural das áreas quilombolas, numa parceria da FOPS com o STTRR então a gente tá junto nessa luta (STTR SANTARÉM, em 22/05/2018).

Os ativismos apresentados pelos movimentos sindicais de Santarém em prol da defesa e preservação dos territórios florestais e de vidas dos povos da floresta configuramse como estratégias de recriação social no interior do modo de produção capitalista, sendo que a manutenção da floresta em pé significa a garantia da subsistência familiar dos povos da/na floresta e a manutenção das práticas agroextrativas. Esse evento geográfico do 
agroextrativismo amazônico é contrário à lógica do agronegócio dos graneis sólidos, resultando em diversificados desencontros conflitantes, pois o setor produtivo não tem como prioridade, na sua agenda, a legislação ambiental e a valorização e respeito aos direitos humanos dos trabalhadores rurais.

Para a liderança do Sindicato dos Trabalhadores e Trabalhadoras Rurais - STTR de Mojuí dos Campos uma das formas de enfrentamento é tornar a terra em seu estágio de produção com as variedades de culturas alimentares e livres de usos de pesticidas e insumos como os utilizados na agricultura das commodities. Contudo, se o agricultor (camponês) não produzir autonomamente, ele não conseguirá se manter na terra e nem sustentar a família. Deste modo, organizam uma produção diversificada (policultura) e a comercialização dos produtos ocorre através de cooperativas e feira livre aonde se constata que os agricultores estão organizados e conseguem trabalhar em parcerias.

A luta por políticas sociais (especificamente educação e saúde) e políticas agrárias (assistência técnica e financiamentos e/ou custeios para ampliar as atividades produtivas) também corresponde a uma das pautas do movimento sindical do munícipio de Mojuí dos Campos, objetivando consolidar a reprodução dos sujeitos nos seus respectivos territórios. Essas estratégias de resistência são imprescindíveis nesse processo de despojo, porque as políticas públicas estão mais a serviço do agronegócio do que para atender aos anseios dos povos do campo.

O munícipio de Mojuí ainda tem 20 comunidades sem energia elétrica e são as comunidades que estão do lado da barragem do rio Curua-úna, e a hidrelétrica de Curua-úna já está lá há quase 50 anos. Então há uma luta também nossa pra essa energia chegar lá, para poder ter uma qualidade de vida melhor, então é um conjunto de ações que a gente trabalha para alcançar as políticas públicas. A educação é precária e tem escolas que além de multisseriado, o professor dá aula e faz a merenda em pleno séc. $X X I$ isso a 40 quilômetros de Santarém. Quanto à questão saúde a gente faz luta também, o município não possui nenhum hospital, existe um prédio há duas décadas mais ou menos que já passou por cinco reformas, mas até hoje não funciona o hospital (STTR - MOJUÍ DOS CAMPOS, em 22/05/2018).

Além da territorialização das lutas dos sindicatos dos trabalhadores rurais dos munícipios de Santarém, Mojuí dos Campos e Belterra, há também uma assessoria jurídica popular, a ONG Terra de Direitos, que presta assessoria de documentos para os povos e comunidades rurais, com a finalidade de garantir a defesa dos direitos humanos e tem atuado no acompanhamento dos enfrentamentos e dos processos de violações dos direitos agrários e territoriais que colocam em ameaça as (re)existências dos povos do campo, das águas e das florestas no oeste paraense. 
Essa ONG atua nos processos e entra com pedidos de assistência no município de Santarém. Auxiliam no processo que discute a questão dos Portos do Maicá, Santarém/PA e Miritituba, Itaituba/PA (Figura 4), almejando contribuir com as formas de resistências nos múltiplos territórios.

Figura 4 - Mapa de localização dos complexos portuários em Santarém/PA e Itaituba/PA

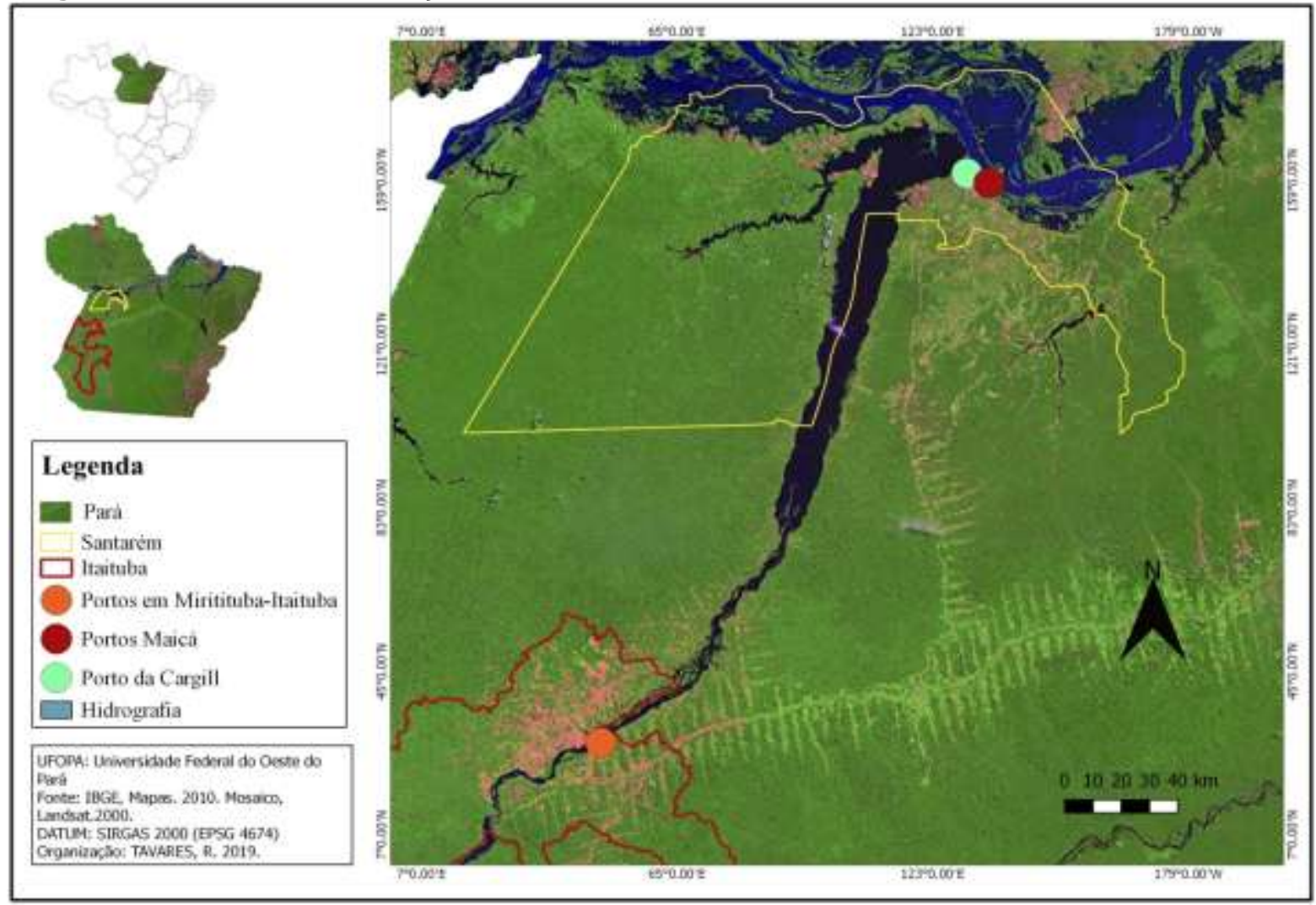

Fonte: elaborado por Tavares a partir de IBGE (2010).

Todavia, essa organização não é a principal protagonista das lutas travadas pelos movimentos sociais, devendo a manifestação e a representação social ser oriunda das próprias demandas e inciativas dos movimentos. Mas acabam dando suporte no processo de fortalecimento dessas lutas, na medida em que acompanham as ocorrências que são disputadas por meio jurídico. Sendo assim:

Se não fossem os movimentos sociais de Santarém, as custodias sociais, movimento indígena e quilombola, pescadores, sindicatos, se não fosse os movimentos em fevereiro do ano de 2016 terem dado um grito muito forte para impedir a realização da audiência pública para conseguir suspender o processo de licenciamento ambiental na justiça, não saberíamos hoje em que pé estaria na discussão dos portos do Maicá (ONG - TERRA DE DIREITOS, em 22/05/2018).

Se não bastasse a expansão do cultivo de grãos no espaço agrário e florestal, os projetos logísticos e o desenvolvimento das redes de infraestruturas na contemporaneidade 
representam a territorialização de monopólios que desestruturam territorialidades indígenas, quilombolas, ribeirinhas, camponesas e caboclas, que tem a natureza como forma de reprodução social da vida. Nesse sentido, os movimentos sociais e algumas organizações atreladas a esses segmentos têm manifestado apoio e contribuído com o fortalecimento das lutas frente à territorialização do capital.

A ONG Terra de Direitos na região do Lago do Maicá (Figura 5 e Figura 6) tem acompanhado ativamente a discussão da implantação dos portos na margem direita do rio Amazonas (Figura 7) e propiciado assistência jurídica e prescrevendo as ilegalidades apresentadas pelos documentos apresentados pelos responsáveis pelo porto graneleiro, a exemplo da Empresa Brasileira de Portos de Santarém (EMBRAPS) (Figura 8), que é responsável pela instalação e exploração do complexo portuário de caráter privado (CONCEIÇÃO, 2017).

Figura 5 - Local de desova e desenvolvimento dos peixes no Lago do Maicá, Santarém-PA

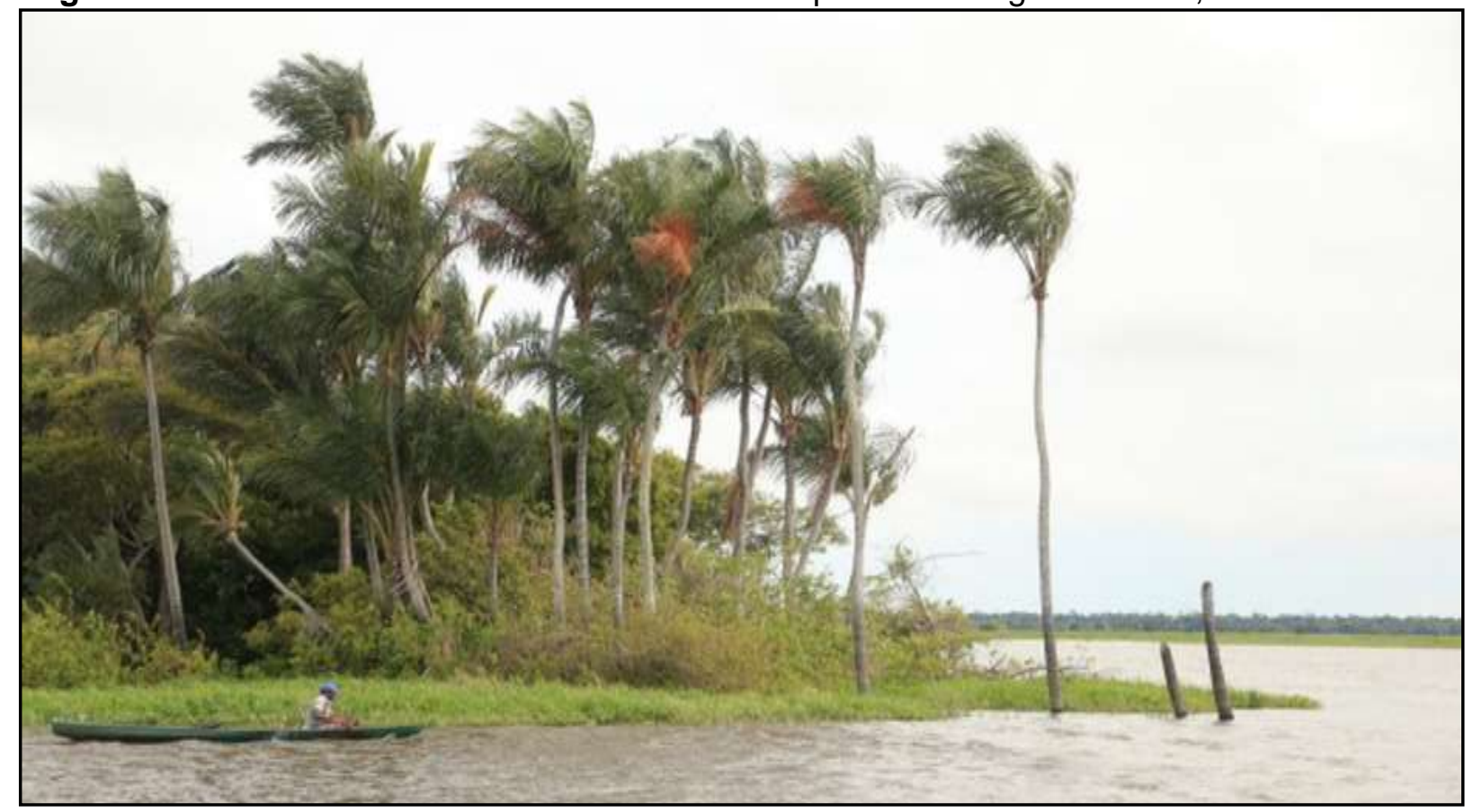

Fonte: Vieira (2018).

As reivindicações dos movimentos sociais e demais organizações afirmam que a construção do terminal portuário privado do agronegócio não vai gerar apenas um impacto de alcance ambiental, mas um impacto eminentemente social, criando mazelas nos territórios das comunidades rurais, bem como tende a afetar, a sociedade em geral do município de Santarém e região.

É evidente o papel e a importância dos movimentos sociais frente à expansão da agricultura capitalista e sistemas de logísticas materializados nos portos que, com o discurso e a proposta hegemônica, nega a existência desses trabalhadores do campo-águas- 
florestas, sua produção espacial, seus modos de vida, suas temporalidades e suas culturas. No entanto, eles se organizam e fazem desses espaços, que o capital tenta se apropriar, um espaço de luta, resistência e sobrevivência na contradição do capitalismo.

Figura 6 - Local previsto para ser construído o terminal privado pela EMBRAPS no Lago do Maicá, Santarém-PA

Fonte: Terra de Direitos (2017).

Figura 7 - Mapa de localização do complexo portuário no Lago do Maicá, Santarém-PA

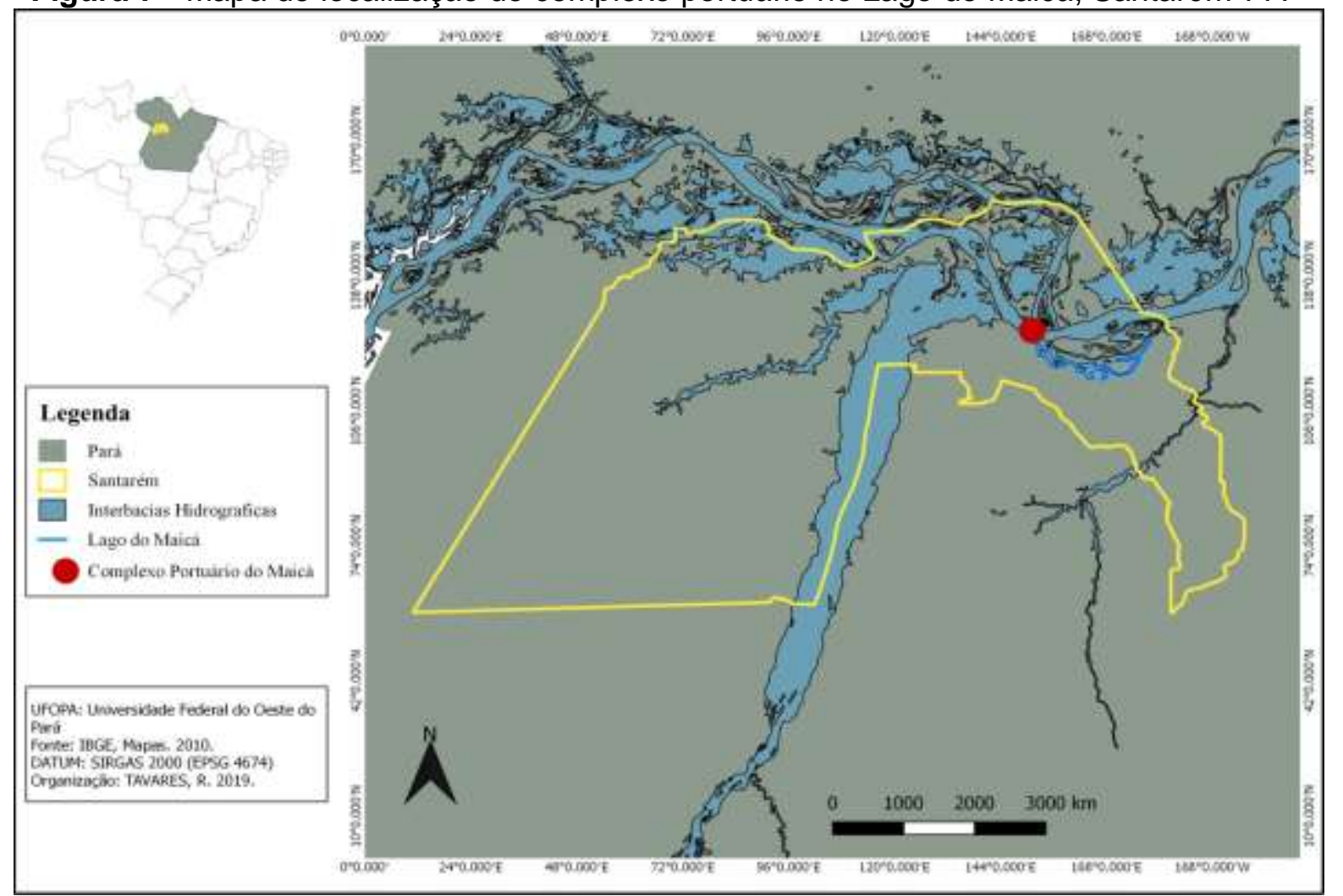

Fonte: elaborado por Tavares a partir de IBGE (2010). 
Figura 8 - Placa da EMBRAPS no Bairro da Área Verde, Santarém-PA, área de influência da construção do complexo portuário

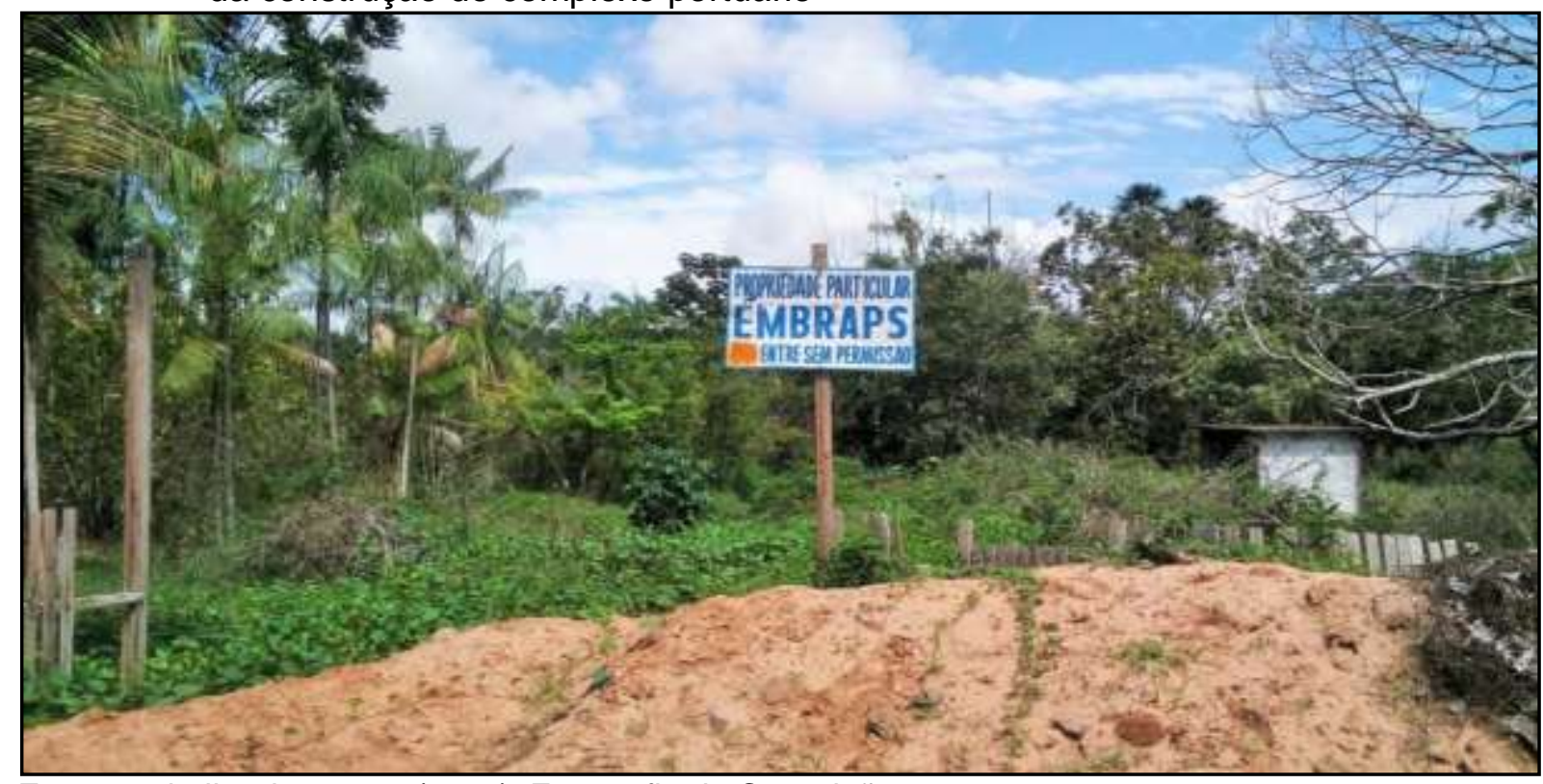

Fonte: trabalho de campo (2016). Fotografia de Conceição.

\section{CONSIDERAÇÕES FINAIS}

A importância dos movimentos sociais e seu grau de organização na região oeste do Pará é bastante evidente, haja vista que há uma expansão desenfreada e sem escrúpulos do agronegócio e corporações apoiados pelo Estado que subjugam e ameaçam os direitos humanos e as territorialidades dos povos do campo (terra), das águas e das florestas. São esses movimentos sociais e demais organizações que se configuram como os principais agentes atuantes e ativos que lutam, resistem e dificultam a ação total do grande capital na região.

As populações da Amazônia, camponesas, indígenas, quilombolas, extrativistas, ribeirinhas e caboclas, vêm sofrendo as pressões territoriais e vêm sendo alvo de violência social e simbólica, pois seus territórios estão ameaçados por uma racionalidade capitalista "moderno-hegemônica" que estabelece rupturas nas territorialidades e espacialidades dos povos e comunidades tradicionais amazônicas. O capital cada vez mais mundializado se reproduz em suas múltiplas dimensões e escalas espaciais e mercantiliza as relações sociais e a natureza. A Amazônia é o reflexo dos conflitos e conflitualidades, fundamentalmente o oeste paraense, pois essa região se configura como a fronteira do capital e o espaço estratégico para a territorialização de projetos hegemônicos mundiais.

A manifestação da Geografia no oeste da Amazônia paraense se configura como a territorialização de monopólios que acaba por promover a monopolização e o estabelecimento de uma ação corporativa no território, nos quais os movimentos sociais 
organizados e demais organizações articulam-se e criam suas estratégias de recriação social das múltiplas territorialidades nos lugares, almejando a garantia pelo reconhecimento de seus direitos agrários e territoriais e de suas permanências e (re)existências na terra/território.

Os estudos e levantamentos realizados nos anos 2017 e 2018, no Planalto Santareno (Santarém, Mojuí dos Campos e Belterra), demostrou que a monocultura do agronegócio da soja, presente na região há mais de 20 anos, tem promovido uma Geografia dos conflitos no campo e nas cidades, o que tem despertado a mobilização e organização das frentes de resistências, os movimentos sociais e as ONGs organizadas. Esses movimentos de lutas de resistências exercem ações efetivas que precisam ser fortalecidas, no momento em que as projeções futuras para o agronegócio voltadas para a região da Amazônia paraense comprometem a vida humana, no que tange os direitos humanos, ambientais e territoriais.

\section{REFERÊNCIAS}

BRASIL. Ministério da Agricultura, Pecuária e Abastecimento. AGE/MAPA. Brasília, DF: MAPA, 2015. Disponível em: https://www.agricultura.gov.b. Acesso em: 15 jan. 2016.

CONCEIÇÃO, F. S. da. A Territorialização do capital e a expansão do agronegócio sojeiro: lutas e (re)existências dos camponeses/camponesas das comunidades Nova Esperança e Nova Aliança no município de Belterra/Pará. 2017. 225f. Dissertação (Mestrado em Geografia) - Fundação Universidade Federal de Rondônia, Porto Velho, RO, 2017.

CONCEIÇÃO, F. S. da; RIBEIRO, A. F. A.; COSTA SILVA, R. G. da. (Des)encontros entre a estrada e o rio: o caso da Gleba da Bota no oeste da Amazônia paraense. Revista

GeoNordeste, São Cristóvão, ano 30, n. 1, p. 6-25, jan./jun. 2019.

FABRINI, J. E. Movimentos sociais no campo e outras resistências camponesas. In: PAULINO, E. T.; FABRINI, J. E. (org.). Campesinato e territórios em disputa. São Paulo: Expressão Popular, 2008. p. 239-272.

FERNANDES, B. M. Construindo um estilo de pensamento na questão agrária: o debate paradigmático e o conhecimento geográfico. 2013. Tese (livre-docência) - Faculdade de Ciências e Tecnologia, Universidade Estadual Paulista, Presidente Prudente, SP, 2013. v. 1 2. Memorial.

FERNANDES, B. M. Entrando nos territórios do Território. In: PAULINO, E. T.; FABRINI, J. E. (org.). Campesinato e territórios em disputa. São Paulo: Expressão Popular, 2008. p. 273-302.

FERNANDES, B. M. Políticas públicas, questão agrária e desenvolvimento territorial rural no Brasil. In: GRISA, C.; SCHNEIDER, S. (org.). Políticas públicas de desenvolvimento rural no Brasil. Porto Alegre: UFRGS, 2015. p. 381-400.

HAESBAERT, R. O mito da desterritorialização: do "fim dos territórios" à multiterritorialidade. Rio de Janeiro: Bertrand Brasil, 2004. 
IBGE. Mapas. 2010. Disponível em:

https://portaldemapas.ibge.gov.br/portal.php\#homepage. Acesso em: 15 jan. 2016.

IBGE. Mapas. 2015. Disponível em:

https://portaldemapas.ibge.gov.br/portal.php\#homepage. Acesso em: 15 jan. 2016.

MARQUES, M. I. M. O conceito de espaço rural em questão. Terra Livre, São Paulo, ano 18, n. 19, p. 95-112, jul./dez. 2002.

OLIVEIRA, A. U. Modo de produção capitalista, agricultura e reforma agrária. São Paulo: LABUR Edições, 2007.

OLIVEIRA, C. M. de.; SANTANA, A. C. de.; HOMMA, A. K. O. Os custos de produção e a rentabilidade da soja nos municípios de Santarém e Belterra, Estado do Pará. Acta Amazônica, Manaus, v. 43, n. 1, p. 25-34, 2013.

PEDON, N. R. Geografia e movimentos sociais: dos primeiros estudos à abordagem socioterritorial. São Paulo: Unesp, 2013.

SCHLESINGER, S.; NORONHA, S. O Brasil está nu! O avanço da monocultura da soja, o grão que cresceu demais. Rio de Janeiro: FASE, 2006.

SOUZA, M. L. de. Autogestão, "autoplanejamento", autonomia: atualidade e dificuldades das práticas espaciais libertárias dos movimentos urbanos. Cidades: Revista Científica, Rio Claro, SP, v. 9., n. 15, 59-93, 2004.

SOUZA, M. L. de. Os conceitos fundamentais da pesquisa sócio-espacial. Rio de Janeiro: Bertrand Brasil, 2016.

TERRA DE DIREITOS. Portos do Maicá. Santarém, PA, 5 maio 2017. Disponível em: https://terradedireitos.org.br/casos-emblematicos/portos-do-maica/15788. Acesso em: 23 mar. 2019.

TEUBAL, M. O campesinato frente à expansão dos agronegócios na América Latina. In: PAULINO, E. T., FABRINI, J. E. (org.). Campesinato e territórios em disputa. São Paulo: Expressão Popular, 2008. p. 139-160.

VIEIRA, S. Estudo técnico da Ufopa aponta 'falhas' no EIA do projeto de construção de porto no Maicá, G1: Portal de Notícias do Grupo Globo, Santarém, PA, 15 maio 2018. Santarém e Região. Notícia. Disponível em: https://g1.globo.com/pa/santarem-regiao/noticia/estudotecnico-da-ufopa-aponta-falhas-no-eia-do-projeto-de-construcao-de-porto-no-maica.ghtml. Acesso em: 23 mar. 2019. 